\title{
Appointment of Pfizer executive to ClHR stirs controversy
}

Published at www.cmaj.ca on Oct. 20

$\mathrm{T}$ he appointment of a senior executive from pharmaceutical giant Pfizer Canada to the governing council of the Canadian Institutes of Health Research (CIHR) has raised concern among some physicians about industry influence at the granting council.

It's a conflict of interest to appoint Dr. Bernard Prigent, vice-president and medical director of Pfizer Canada, to the CIHR council, suggests Dr. Sidney Wolfe, director of the health research group at the Washington, DC-based watchdog organization Public Citizen.

The pharmaceutical industry is a strong advocate for boosting funding for research organizations because basic research supported by public money at universities is often the source of discoveries that are later taken up and commercialized by industry, Wolfe says. Prigent's appointment places an industry representative "directly at the policymaking level and it is not unlikely that someone from Pfizer will recommend things in favour of the drug industry."

Federal Health Minister Leona Aglukkaq earlier this month made Prigent the first pharmaceutical company representative on CIHR's governing council.

The council is responsible for developing CIHR's "strategic directions, goals and policies," approving the budget, appointing scientific directors, creating and terminating institutes and evaluating the organization's performance. CIHR media relations officer David Coulombe says appointments to the 17-member body are made by the federal cabinet, although CIHR's president may advise the health minister on appropriate candidates.

CIHR president Dr. Alain Beaudet told delegates to the 7th Clinical Trial in Canada conference in Toronto, Ontario, on Oct. 19 that the agency hopes to synchronize its activities with the federal government's overall science and tech-

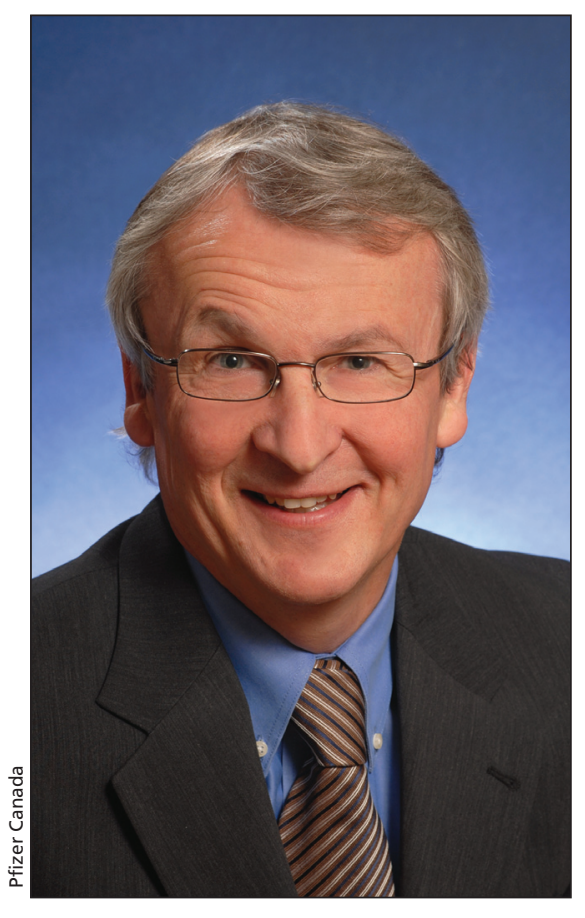

Pfizer Canada Vice-President and Medical Director Dr. Bernard Prigent is the first pharmaceutical company representative to be appointed to the governing council of the Canadian Institutes of Health Research.

nology strategy, Mobilizing Science and Technology to Canada's Advantage. "We also want to ensure closer ties with industry, that they sit at the same table at the precompetitive level. We want to help industry to succeed and encourage them to invest," Beaudet said.

Wolfe notes that while Canada has appointed Prigent to CIHR's governing council, conflict-of-interest policies have been tightened considerably at the United States National Institutes of Health (NIH).

There are currently no industry representatives on the NIH Advisory Committee to the Director, though there have been such members in the past, spokesman Don Ralbovsky stated in an email. "There's nothing in the legislation, or in the Advisory Committee to the Director charter, that prohibits an individual employed at a pharmaceutical or other private firm from serving on a federally chartered committee. However, NIH is aware of the need to be diligent in reviewing meeting agendas for the purpose of conflict of interest and member employment, regardless of whether the member is from industry, academe, government or other entity. All financial information is reviewed very carefully at the service center and the NIH Ethics Office."

Potentially, industry representation on a governing council could skew grant selection, says Dr. Joel Lexchin, a professor at the School of Health Policy and Management at York University in Toronto, Ontario. Lexchin is uncomfortable with Prigent's appointment "because the priorities of the private sector are not necessarily the same as those of the public sector."

For example, debate now revolves around whether publicly funded research should be exclusively licensed to industry or made more widely available through nonexclusive licenses in order to benefit nonprofit groups and facilitate access to products in the developing world, Lexchin says. Meanwhile, the appointment is symptomatic of CIHR placing greater emphasis on public-private research partnerships "and when researchers have to raise money from industry, it means they may skew their priorities to align themselves with what industry is interested in, in order to get grants."

Others say that as long as Prigent isn't directly involved in grant selection, and is confined to broader "policy" discussion, there shouldn't be a problem.

If a governing council has a clear mandate, robust leadership and represents the public interest, it's preferable that "industry had a place" at a relatively transparent table than at "less well-defined meetings between the CIHR board and 'representatives' of industry where they may be a greater potential for influence," Dr. David Henry, president of the Institute 
of Clinical Evaluative Sciences in Toronto, Ontario writes in an email.

Bryn Williams-Jones, assistant professor of bioethics at the University of Montréal's faculty of medicine, says Prigent's appointment may not represent a direct conflict of interest, but it raises the issue of the "vision for a funding council."
"Many of us are critical of the move in CIHR and the SSHRC (Social Sciences and Humanities Research Council) towards the increasing importance of commercialization," he says.

The federal government views universities as "knowledge factories and economic engines," Williams-Jones adds. But governments have a bad track record when they intervene in basic research, which often yields the greatest economic and sociietal benefits. "The reason they give out Nobel prizes 40 years later is because that is when a discovery [in basic science] has an impact." - Ann Silversides, CMAJ

DOI:10.1503/cmaj.109-3085 